\title{
Posttraumatic stress and depression in Yazidi refugees
}

\author{
This article was published in the following Dove Press journal: \\ Neuropsychiatric Disease and Treatment \\ 14 November 2016 \\ Number of times this article has been viewed
}

\author{
Serhat Nasıroğlu' \\ Veysi Çeri² \\ 'Department of Child and Adolescent \\ Psychiatry, Faculty of Medicine, \\ Sakarya University, Sakarya, Turkey; \\ ${ }^{2}$ Pendik Training and Research \\ Hospital, Department of Child and \\ Adolescent Psychiatry, Medical School \\ of Marmara University, Istanbul, \\ Turkey
}

Aim: The aim of this investigation was to determine the frequency of mental pathologies in children and adolescents of the Yazidi minority group who immigrated to Turkey from Iraq. The refugees were asked about preventive and risk factors that occurred before and after their immigration.

Subjects and methods: The sample comprised 55 children and adolescents (30 males and 25 females) who were Yazidi refugees and had settled in the Uçkuyular, Oğuz, Onbaşı, and Ugurca villages of Batman, Turkey. The study was conducted 9 months after the refugees had immigrated. The participants were evaluated in their native language through a semistructured interview titled "Reliability and Validity of Schedule for Affective Disorders and Schizophrenia for School-Age Children - Present and Lifetime Version - Turkish Version". A sociodemographic form was prepared so that investigators could understand their traumatic experiences before and after the migration and their current social conditions. All the interviews were conducted in the participants' native language without the help of translators. The investigators filled out the sociodemographic forms.

Results: Posttraumatic stress disorder (PTSD) was detected in 20 children (36.4\%), depression in $18(32.7 \%)$, nocturnal enuresis in six $(10.9 \%)$, and anxiety in four $(7.3 \%)$. The following factors were found to be associated with depression: witnessing violence and/or death, being a girl, having older parents, being the elder child, and having multiple siblings $(P<0.05)$. Risk factors for PTSD, depression, and comorbid conditions included witnessing violence and/or death $(P<0.05)$. Four participants were observed to have both PTSD and depression $(7.3 \%)$.

Conclusion: Most of the refugee children had experienced serious traumatic events in their home country. PTSD, depression, and comorbid mental problems are frequently seen in refugee children.

Keywords: refugees, child and adolescent, PTSD, depression, risk factors

\section{Introduction}

Under the 1951 Refugee Convention and its 1967 protocol, refugees are people who cannot return to their countries, due to a well-founded fear of persecution because of their race, religion, nationality, social group, or political ideas. ${ }^{1}$ The number of studies on refugee children and how to evaluate and integrate them into their host countries is limited. Traumatic life events for such children before their migration may include exposure to violence, separation from family and friends, and cessation of studies. ${ }^{2}$ Separation from their home environment causes traumatic experiences by interrupting their attachment to home, putting distance between them and their friends, and damaging their feelings of individualism toward a place where they have been living for a long time. ${ }^{3}$ The needs of refugee children and adolescents during their resettlement should be satisfied in such a way that they can continue their lives in a safe area. ${ }^{4}$
Correspondence: Serhat Nasıroğlu Department of Child and Adolescent Psychiatry, Faculty of Medicine, Sakarya University, Sakarya 54000, Turkey Tel +90505 5681072

Email serhatnasiroglu@gmail.com BY
you hereby accept the Terms. Non-commercial uses of the work are permitted without any further permission from Dove Medical Press Limited, provided the work is properly attributed. For

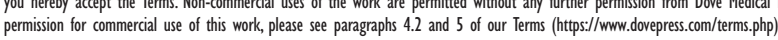


The frequency of posttraumatic stress disorder (PTSD) during a lifetime has been found to be $1 \%-1.3 \%$ in groups that are not at risk. ${ }^{5}$ While most refugee children are in developing countries, studies on adolescents under 18 years of age and children have generally been conducted on heterogeneous groups with different migration stories and ethnic origins. In such studies, PTSD has been detected in approximately $11 \%$ of refugee children. There may be a loss of functioning in the families of PTSD victims and an increase in mental disorders, including low self-respect, in their children. ${ }^{6}$ In a study on 46 Cambodian children living in the US 6 years after their first evaluation, 46\% showed symptoms of PTSD; 12 years later, $35 \%$ had PTSD. The frequency of depression at the same time points was $7 \%$ and $14 \%$, respectively. ${ }^{8}$ In a study from Belgium, refugee children and adolescents who were unaccompanied were found to have anxiety problems, depression, PTSD symptoms, emotional and developmental problems, and fivefoldgreater risk of these diagnoses than children and adolescents living with their families. ${ }^{9}$

In studies of children, PTSD frequency has been found to be $3 \%-37 \%$, depending on their country of origin, culture, norms, and coping strategies. ${ }^{10}$ After long wars or during ongoing organized violence, the frequency of PTSD among this population was reported to be $18 \%-70 \% .^{11}$

Terr ${ }^{12}$ explained that traumatic experience in children is of two main types. Type 1 (event stress) is experienced in childhood after a sudden, single, unexpected, and unaddressed stress factor. Type 2 is caused by longer term and recurrent stress factors that may come in the form of psychological or sexual abuse. Refugee children and adolescents have generally experienced type 2 traumas, even before migration, and these traumas may continue during and after settlement. ${ }^{12}$ The children and adolescents often relax when they reach a new country: a feeling of hope develops, because the war and dangerous life conditions have been left behind, uncertainties have ended, and new opportunities await. However, a short time after arriving in the new country, these individuals often feel they will have problems adapting to the different culture of the new society. These problems include different social structures, school systems, role models, cultural habits, rules, traditions, and language. ${ }^{13}$

In Turkey, refugees who live in camps are divided into two groups: municipalities accommodate one, and the other lives in the camps of the Disaster and Emergency Management Presidency. According to data from the latter, in 2015, 258,537 refugees were living in Turkish camps: 36,460 in Kilis, 15,087 in Hatay, 49,956 in four tent camps and one container camp in Gaziantep, 14,000 in Şanlıurfa, and 17,295 in a central tent city in Kahramanmaraş. Most of the Yazidi population resided in the Sinjar district of Iraq.

It is estimated that there are $800,000-1$ million Yazidi people worldwide. Their religious beliefs are orally maintained by their clerics; therefore, there are few written documents on the Yazidi belief system or the history of the Yazidi population. ${ }^{14}$ We investigated the frequency of postwar PTSD, anxiety, and depression in Yazidi children and adolescents who settled in four Turkish villages after the war.

\section{Subjects and methods Participants}

The Uçkuyular, Oğuz, Onbaşı, and Uğurca villages of Batman, Turkey are located close to one another and accommodate people of similar religious beliefs and economic and social conditions. The Yazidi people living in these villages were regularly visited for 10 days in the ninth month after their immigration by two child and adolescent psychiatrists who could speak their native language. All 58 Yazidi houses with children and adolescents were visited, with feedback from local administrators, and 46 met the study criteria. There were a total of 127 Yazidi children and adolescents under the age of 18 years in the villages where the study was conducted. Refugee children and adolescents who had mental retardation or autism were not included in the study. A total of 55 children and adolescents participated in the study, with 17 of these participating with their siblings: seven families each had two siblings participate, and one family had three siblings participate. The interviews were conducted at the participants' homes under appropriate mental examination conditions. All adolescents agreed to participate in the study by providing written informed consent. Child assent was obtained as well as written informed consent which was sought on behalf of children under 18 years of age from a parent or guardian. The permission and cooperation of village officials was obtained. This study was approved by the ethics committee of Sakarya University.

\section{Demographic information}

The sociodemographic data of the participants was evaluated using a sociodemographic data form prepared by the investigators. The participants were asked whether any of their relatives had died during the war, whether they believed they would ever return to their countries of origin, whether they lived with their families in the village, whether they went to school before they arrived, and whether they had witnessed battles with gunfire or bombings. The families were asked whether their child had any prior psychiatric diagnoses, and questions were aimed at determining risk and protective factors before and after migration. 


\section{Assessment}

The Kiddie Schedule for Affective Disorders and SchizophreniaPresent and Lifetime (K-SADS-PL) was adapted from the Present Episode version of the K-SADS (K-SADS-P). ${ }^{15}$ The Turkish version of the K-SADS-PL was used in this study. The translator demonstrated the reliability and validity of this version. ${ }^{16}$ The first section, the "unstructured initial interview", included information on demographic data, health status, current complaints, and past psychiatric treatment, along with the position of the children at school, their hobbies, and their relationships with friends and family.

The second section, which is diagnosis-oriented, evaluated 200 specific symptoms and behaviors. If positive symptoms were present at screening, additional scoring was done in five diagnostic areas to verify the diagnosis: mood disorders, psychotic disorders, anxiety disorders, substance-abuse disorders, and other disorders (enuresis, encopresis, anorexia nervosa, bulimia, temporary tic disorders, Tourette's syndrome, chronic motor or vocal tic disorder, PTSD, and adaptation disorder). ${ }^{17}$

The semistructured interview (K-SADS-PL-T) was conducted by two pediatric and adolescent psychiatrists who could speak Kurdish, the native language of the Yazidi refugees. In accordance with recommendations, the interviews were first done with the parents of the preadolescent children and then with the children; interviews were first done with the adolescents and then with their parents.

\section{Statistical analysis}

Descriptive analyses were performed on the general characteristics of the study population. The Kolmogorov-Smirnov test was used to evaluate whether the distribution of variables was normal. The Mann-Whitney $U$ test compared demographic characteristics and other continuous data between the groups. Continuous data are presented as mean \pm standard deviation. Categorical data were compared by Pearson's $\chi^{2}$, Yates's correction, or Fisher's exact $\chi^{2}$ tests, and are presented as counts and percentages. Risk factors associated with depression were evaluated with a linear regression model. A $P$-value $<0.05$ was considered significant.

\section{Results}

\section{Descriptive statistics}

All 55 children and adolescents who met the study criteria participated voluntarily. The trust resulting from both the researchers and local officers speaking the same language as the refugees may have resulted in the high response rate. The 55 participants were aged 6-17 years, with a mean age of $11( \pm 3.67)$ years. When participants were grouped, $32(58.2 \%)$ were listed as children, and $23(41.8 \%)$ were listed as adolescents. Of the participants, $30(54.5 \%)$ were males, and 25 (45.6\%) were females. None of the participants was attending school at the time of their interviews; 42 (76.4\%) participants went to school before their migration, and $13(23.6 \%)$ did not.

The participants had between two and 12 siblings. Half of them (49.1\%) had between four and six siblings, and 40 (72.7\%) had up to three children in their family. Fifty-four participants (98.2\%) said they had friends in the villages. A total of $32(58.2 \%)$ participants reported being happy in the villages, 18 participants (32.7\%) reported being unhappy, and five $(9.1 \%)$ reported being uncertain of their level of happiness. None of the participants knew Turkish.

The frequency and ratio of the participants' answers about specific war conditions are presented in Table 1. Twelve

Table I Descriptive analysis results

\begin{tabular}{|c|c|}
\hline Questions/answers & Frequency \\
\hline \multicolumn{2}{|c|}{ Did any relative/friend die during the war? } \\
\hline From the core family & $12(21.8 \%)$ \\
\hline Relative, neighbor, friend & $43(78.2 \%)$ \\
\hline \multicolumn{2}{|c|}{ Are there persons where you came from for whose safety you } \\
\hline \multicolumn{2}{|l|}{ feel afraid? } \\
\hline Yes & $46(83.6 \%)$ \\
\hline No & $9(16.4 \%)$ \\
\hline \multicolumn{2}{|c|}{ Were you exposed to ill treatment or torture during the war } \\
\hline \multicolumn{2}{|l|}{ or migration? } \\
\hline Yes & $4(7.3 \%)$ \\
\hline No & $51(92.7 \%)$ \\
\hline \multicolumn{2}{|c|}{ Have you seen a dead or wounded person? } \\
\hline Yes & $25(45.5 \%)$ \\
\hline No & $30(54.5 \%)$ \\
\hline \multicolumn{2}{|c|}{ Have you seen anyone being exposed to ill treatment or being } \\
\hline \multicolumn{2}{|c|}{ killed? } \\
\hline Yes & $14(25.5 \%)$ \\
\hline No & $4 \mathrm{I}(74.5 \%)$ \\
\hline \multicolumn{2}{|c|}{ Did you witness any skirmishes or bombing where you came } \\
\hline \multicolumn{2}{|l|}{ from? } \\
\hline Yes & $53(96.4 \%)$ \\
\hline No & $2(3.6 \%)$ \\
\hline \multicolumn{2}{|c|}{ How afraid were you during the war/migration? } \\
\hline None & $3(5.5 \%)$ \\
\hline A little & I (I.8\%) \\
\hline Considerably & $4(7.3 \%)$ \\
\hline Very much & $47(85.5 \%)$ \\
\hline \multicolumn{2}{|c|}{ Was anyone near you wounded during the war/migration? } \\
\hline Yes & $14(25.5 \%)$ \\
\hline No & $4 \mathrm{l}(74.5 \%)$ \\
\hline \multicolumn{2}{|c|}{ Were you ever homeless/foodless after the war/migration? } \\
\hline Yes & $52(94.5 \%)$ \\
\hline No & $3(5.5 \%)$ \\
\hline \multicolumn{2}{|c|}{ Were you alone during the war/migration? } \\
\hline Yes & I (I.8\%) \\
\hline No & $54(98.2 \%)$ \\
\hline \multicolumn{2}{|c|}{ Do you believe that the war will end? } \\
\hline Yes & $18(32.7 \%)$ \\
\hline No & $37(67.3 \%)$ \\
\hline \multicolumn{2}{|c|}{ Do you believe that you will return to your country? } \\
\hline Yes & I7 (30.9\%) \\
\hline No & 38 (69.1\%) \\
\hline
\end{tabular}


(21.8\%) had lost their mother, father, or a sibling, and 43 (78.2\%) reported deaths among relatives, friends, and/or neighbors.

When the frequency and percentages of the participants' answers about their parents were evaluated, the mean age of the mothers was found to be $36.05( \pm 9.27)$ years, and the mean age of the fathers was 39.37 ( \pm 9.28$)$ years. Having older parents was found to be significant in terms of depression $(P<0.05)$. According to the questionnaire, 18 participants $(32.7 \%)$ were not diagnosed with anything, while $37(67.3 \%)$ were. Tables 2 and 3 show the frequency and rates of the diagnoses.

\section{Group comparisons}

In this section, the demographic characteristics, including sex and age groups, are presented, as well as participants' and parents' answers to questions about before and after their migrations and a comparison of the distribution of the participants' diagnoses.

\section{Sex}

There was a significant difference in the answers of male and female participants to the question "Is there anyone left from where you came for whose safety you feel concerned?" $\left(\chi^{2}=3.597, d f=1, P=0.031\right)$. Females were feeling more concerned about the people they left from where they came from; compared to males. There was also a significant difference in the answer of the participants to the question "Was anyone near you during the war/migration wounded?" $\left(\chi^{2}=10.1, d f=1, P=0.006\right)$, to which a higher number of females answered yes.

The distribution of sexes according to diagnostic groups was analyzed with $\chi^{2}$ tests. There was a significant difference in obtaining an established diagnosis between male and female participants $\left(\chi^{2}=7.301, d f=1, P=0.007\right)$ : more females had an established diagnosis. There was also a significant difference between male and female participants in number

Table 2 Frequency and rates of diagnosis in participants

\begin{tabular}{ll}
\hline Diagnosis $^{\mathbf{a}}$ & Frequency \\
\hline PTSD & $20(36.4 \%)$ \\
Depression & $18(32.7 \%)$ \\
Nocturnal enuresis & $6(10.9 \%)$ \\
Specific phobia & $4(7.3 \%)$ \\
Anxiety & $4(7.3 \%)$ \\
ADHD & $1(1.8 \%)$ \\
\hline
\end{tabular}

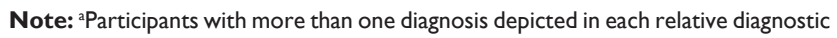
group separately.

Abbreviations: PTSD, posttraumatic stress disorder; ADHD, attention deficit/ hyperactivity disorder.
Table 3 Rates of diagnosis and comorbidity

\begin{tabular}{ll}
\hline Diagnosis & Frequency \\
\hline Without a diagnosis & I8 (32.7\%) \\
Those with only PTSD diagnosis & II (20\%) \\
Those with only depression diagnosis & II (20\%) \\
Those with only specific phobia diagnosis & $2(3.6 \%)$ \\
Those with comorbidities & \\
Depression + PTSD & $4(7.3 \%)$ \\
PTSD + anxiety & $2(3.6 \%)$ \\
Depression + nocturnal enuresis & $\mathrm{I}(\mathrm{I} .8 \%)$ \\
Anxiety + nocturnal enuresis & $\mathrm{I}(\mathrm{I} .8 \%)$ \\
ADHD + nocturnal enuresis & $\mathrm{I}(\mathrm{I} .8 \%)$ \\
Depression + PTSD + anxiety & $\mathrm{I}(\mathrm{I} .8 \%)$ \\
Nocturnal enuresis + specific phobia & $\mathrm{I}(\mathrm{I} .8 \%)$ \\
Depression + PTSD + specific phobia & $\mathrm{I}(\mathrm{I} .8 \%)$ \\
Total & $\mathbf{5 5}$
\end{tabular}

Abbreviations: PTSD, posttraumatic stress disorder; ADHD, attention deficit/ hyperactivity disorder.

of diagnoses $\left(\chi^{2}=18.465, d f=1, P=0.000\right)$ : generally, males did not have a diagnosis.

\section{Age groups}

The distribution of answers of the children (6-12 years old) and the adolescents (13-17 years old) were analyzed with $\chi^{2}$ tests. The school attendance of children and adolescents before settling in these villages showed significant differences according to the frequency found in the analysis and $\chi^{2}$ evaluation $\left(\chi^{2}=6.415, d f=1, P=0.011\right)$. There was also a significant difference between children and adolescents in terms of living with their families in these villages $\left(\chi^{2}=4.868, d f=1, P=0.015\right)$. Adolescents were more likely than children to be living with their parents. There was a significant difference between children and adolescents in terms of number of siblings $\left(\chi^{2}=18.048, d f=3, P=0.000\right)$ : children generally had one to three siblings, while adolescents generally had four to six.

The distribution of children and adolescents according to diagnostic groups was analyzed with $\chi^{2}$ tests. There was a significant difference between having at least one diagnosis of psychiatric disorder, depression, and nocturnal enuresis. Frequencies obtained as the result of analysis are presented in Table 4.

\section{Factors before and after migration}

Distribution the answers of participants and their parents to questions about before and after the migration was analyzed with $\chi^{2}$ tests. Their educational status in terms of continuing school before and after migration could not be analyzed, as no participants went to school after their migration. 
Table 4 Frequency of diagnosis in children and adolescents and $\chi^{2}$-analysis results

\begin{tabular}{llll}
\hline Diagnosis $^{\mathbf{a}}$ & Children (n=32) & Adolescents (n=23) & P-value \\
\hline Diagnosis & & & \\
No & $15(46.9 \%)$ & $3(13 \%)$ & 0.019 \\
Yes & $17(53.1 \%)$ & $20(87 \%)$ & \\
Depression & & & \\
$\quad$ No & $29(90.6 \%)$ & $8(34.8 \%)$ & 0.000 \\
Yes & $3(9.4 \%)$ & $15(65.2 \%)$ & \\
Nocturnal enuresis & & \\
No & $26(81.2 \%)$ & $23(100 \%)$ & 0.035 \\
Yes & $6(18.8 \%)$ & 0 & \\
\hline
\end{tabular}

Note: aparticipants with more than one diagnosis included in each diagnostic group separately.

\section{Groups with and without diagnoses}

Distribution of answers to questions specific to the war/ migration condition of groups with and without a diagnosis was examined with $\chi^{2}$ analysis. Only answers to the question "Have you seen anybody exposed to violence or murder?" showed a statistically significant difference $\left(\chi^{2}=4.133, d f=1\right.$, $P=0.022)$. The number of "Yes" answers was higher in the group with diagnoses versus the group with none.

\section{Factors affecting depression}

Multiple logistic and linear regression analyses were performed to explore the predictive values of independent variables on the development of depression. Among the factors associated with depression (witnessing others exposed to violence or death, being female, having parents of an older age, having a higher number of siblings), the age of the child and being the older sibling were found to be risk factors for depression in the linear regression analysis (for age, $\beta=-0.385, t=-2.154$, adjusted $R^{2}=0.243 ; P<0.05$ ), as shown in Table 5 .

\section{Discussion}

The aims of this study were to determine the frequency of mental health problems in refugee children and to detect

Table 5 Multiple linear regression analyses of risk factors for depression

\begin{tabular}{llll}
\hline Model & \multicolumn{3}{l}{ Standardized coefficients } \\
\cline { 2 - 4 } & $\boldsymbol{\beta}$ & $\boldsymbol{t}$ & Significance \\
\hline Constant & & 4.193 & 0 \\
Witnessing violence & 0.85 & 0.595 & 0.554 \\
Sex & -0.156 & -1.083 & 0.284 \\
Rank among siblings & 0.123 & 0.874 & 0.387 \\
Age & -0.385 & -2.154 & 0.036 \\
Mother's age & 0.16 & 0.737 & 0.465 \\
Father's age & -0.275 & -1.398 & 0.169 \\
\hline
\end{tabular}

Note: Depression was the dependent variable. risk factors and protective factors by understanding their prewar and postwar experiences. There were swift and sudden assaults on Yazidis in 2014 by the group calling themselves "Islamic state" in the Sinjar region of northern Iraq. As a result, thousands of civilians were killed, and some females and children were sold as slaves. At the time of our interviews, the refugees could not attain legal refugee status, although nearly 9 months had passed since the Sinjar attacks.

Origins and devotion to ideological responsibilities may play a protective mental health role during resettlement. ${ }^{18}$ In a study on Tibetan refugees who had resettled in India, their religious beliefs, contribution to society, and sense of solidarity against the oppression of Tibet were found to help reduce mental problems in their children. ${ }^{19}$ The reason for the Yazidi refugees to settle in these four villages was that there were already populations of Yazidi people present. These individuals preferred living here together with their relatives, instead of settling in camps constructed by Turkey or local municipalities. This choice was initially thought to be a protective factor, but was later believed to increase mental pathologies, due to the isolation of children and adolescents and their being unable to attend school and receive social support.

The relationships among age, sex, and mental problems may differ in different studies. In a small number of studies, refugees $<12$ years of age were shown to do better in terms of mental illnesses, such as depression, versus older children. Still, the relationship between these results and the increase in depression and anxiety during the transition from childhood to adolescence should be investigated. ${ }^{20}$ In nearly half the studies on children, mental health problems - especially depression - were more frequently observed in girls. ${ }^{21-24}$ A significant difference existed between males and females in this study in terms of diagnosis, as well: more female children were diagnosed with a mental illness. There was also a significant difference between males and females in terms of the number of diagnoses. It is believed that one cause of this was that females were less socialized than males into the village environment.

The determination of a relationship between age and mental illnesses is difficult, because of factors such as different ages at migration, mechanisms of decision making in migrated countries, and places of settlement. A finding of a study of a refuge center in England showed that children $<15$ years of age experienced problems more frequently compared with children aged $15-17$ years. ${ }^{25}$ The current study found that adolescents (aged 13-17 years) were 
diagnosed with depression significantly more than children (aged 6-12 years). Adolescents had to provide food and water and protect other family members during their escape, which may have led them to see more acts of violence, and witnessing others being exposed to violence or death was found to be a risk factor for depression in adolescents.

Another important point in terms of individual risk factors is the education of these children. Education is an important protective factor, as most of the refugees had experienced serious traumatic events in their home countries. Generally, they were forced to leave their homes and flee as a result of the war. During this process, they witnessed violence and torture and experienced the loss of close relatives and friends. Refugee children do not have memories of life and school life; even if they attended, their education has been interrupted. ${ }^{26}$ Refugees fled together with the aim of safely reaching a neighboring or close country that would provide them protection. ${ }^{27}$

Refugees' traumas are not experienced individually, but as events that accumulate and are interrelated. These events may shake the feelings of refugees about staying strong, their identities, and the meaning of life. ${ }^{28}$ When the traumatic experiences of children and adolescents before the migration were examined in this study, 46 participants (83.6\%) said yes to the question "Did you leave anybody whose safety you are concerned about?" A total of 25 participants (45.5\%) reported seeing a dead or wounded person, 14 (25.5\%) reported seeing people exposed to violence or being killed, and a high number (53 [96.4\%]) reported having witnessed armed skirmishes or bombings. In this study, witnessing someone being exposed to violence or being killed was significantly high, especially among the population diagnosed with depression. Nevertheless, in a follow-up study by Montgomery on 131 refugees living in Denmark 8-9 years after fleeing their countries, social experiences and stresses in Denmark were found to be more decisive in the development of mental problems than those experienced before migration. ${ }^{29}$

Fazel et al investigated the mental pathologies of refugee children and adolescents in 2005 by studying 260 refugee children aged between 7 and 17 years, who had migrated from Bosnia, Central America, Iran, Kurdistan, and Rwanda and settled in Western countries. The rate of PTSD among these children was found to be $11 \%{ }^{30}$ In a similar follow-up study on 46 Cambodian children living in the US, PTSD was detected in $46 \%$ of them 6 years after the first evaluation, and found in 35\% 12 years after the first evaluation; the rates of depression were $7 \%$ and $14 \%$ at these evaluations, respectively. ${ }^{8}$
In a meta-analysis of 37 studies including a total of 24,051 refugees, depression and anxiety were twice as prevalent in refugees versus those who had migrated for economic reasons. The gross national product of the country in which refugees settled was not found to have any effect on the mental health of refugees, but the mental health of those who migrated for economic reasons was found to be affected by this factor. ${ }^{31}$

In a study on Bosnian children who were victims of ethnic "cleansing", high rates of PTSD (65\%) and depression $(35 \%)$ were found 1 year after their migration to the $\mathrm{US}^{32}$ In a study in Norway of male adolescent refugees, at least one psychiatric disorder was found in $41.9 \%$ of the participants, PTSD in $30.6 \%$, mood disorders in $13.8 \%$, and anxiety disorder in $13.8 \%{ }^{33}$ From a mental health perspective, experiencing war, violence, murders, and/or torture increases the risk of psychiatric disorders and damages those who are exposed. ${ }^{34}$

In accordance with the literature, in this study PTSD was detected in 20 participants (36.4\%), depression in 18 (32.7\%), nocturnal enuresis in six (10.9\%), and anxiety in four $(7.3 \%)$. We believe that insufficient social support, the distance between the refugees' settlement areas and the city center, differences in religious beliefs, the inability of the children to attend school, and economic difficulties have increased the rate of mental illness diagnoses. When studies on refugees are examined, it is reported that enuresis, which increases during stress conditions, has not been sufficiently investigated. ${ }^{35}$ In this study, enuresis was detected in six participants $(10.9 \%)$ in whom there were no diagnoses or complaints of enuresis prior to our examination.

The rates of depression and anxiety in refugees are different in various studies, and have been shown to be possibly associated with the financial conditions of the country in which the refugees have settled. In a meta-analysis, rates of depression were $20 \%$ in worker immigrants and $44 \%$ in refugees, and the prevalence of comorbid anxiety was $21 \%$ in worker immigrants and $40 \%$ in refugees $(n=24,051) .{ }^{31}$ In a similar study, the comorbidity of PTSD and depression was found to be $34 \%$ in refugee adolescents from Afghanistan. ${ }^{36}$ In that study, PTSD and depression were the most frequently seen comorbidities. PTSD and depression comorbidity $(7.3 \%)$ were less frequent in our study.

In studies on refugees, the most extensively investigated diagnoses are PTSD, other anxiety disorders, and depression. Comorbidities are prevalent, and different symptoms of multiple disorders may be seen in refugee children. ${ }^{26}$ Similarly to other studies, the number of participants in this 
study with one diagnosis was $24(43.6 \%)$, the number of those with two diagnoses was ten $(18.2 \%)$, and the number with three diagnoses was three $(5.5 \%){ }^{36}$

Economic processes after migration may affect children's psychological functions. Familial concerns about economic problems may exert negative effects on the mental health of refugee children. It has been suggested that for this reason, Bosnian adolescent refugees with a lower socioeconomic status showed more depressive symptoms and had lower self-esteem. ${ }^{37}$ In accordance with earlier studies, especially the Bosnian study, the presence of a higher number of siblings may be evidence of lower socioeconomic family status.

Another interesting point in our study was that none of the children was attending school. While nongovernmental organizations provided educational support in camps near the villages inhabited by Yazidi children, no such support existed for the villages themselves. Restarting school-age children's education without losing time after their status assessment is important. School is a safe haven for refugee children against hardship, uncertainty, and chaos. School reminds these children of a stable and habitual life, decreases traumatic symptoms, facilitates turning foreign children into citizens, and enables them to adapt to society. Attending school also satisfies their need to belong to a social group, and helps them look to the future with hope. ${ }^{38}$

The high rate of diagnoses among these children suggests the importance of increasing social support in the villages and the importance of schools. A standout point in this study was that none of the participants knew Turkish. We believe one reason for this was the absence of a school life; another is that the residents of these villages spoke their mother language, so they did not find it necessary to learn the country's dominant language.

\section{Limitations of the study}

While all the children who had settled in four Turkish villages, except those with a diagnosis of mental retardation or autism, were screened, clinical interviews were conducted with a relatively small number of participants overall. For this reason, the significance of protective and risk factors before and after migration, which were included in the sociodemographic form, could not be determined. At the same time, because of low literacy rates among the parents and participants, screening scales for mental trauma could not be used. Not every family member of the Yazidi refugee children was able to migrate, and some children migrated to other countries. Therefore, not all children in each family could be evaluated.

\section{Conclusion}

In recent years especially, we have been observing a prominent wave of migration from Syria and Iraq to developed countries in Europe and North America, because of the increasing severity of various wars. Society should know and internalize the fact that the right to migrate is the most basic human right. It is well known that children and adolescents lose their lives, become separated from their relatives, and are exposed to ill-treatment during migration. As the first study on Yazidi refugees, we find that social support for these children and adolescents should be increased, discrimination and "othering" by the press should be terminated, and schooling should be provided. Larger scale studies with more refugee children and adolescents as participants should be conducted with the aim of detecting risk and protective factors that can cause or decrease mental disorders.

\section{Acknowledgments}

We thank the local village authorities who helped us to find the homes of refugee children and adolescents that settled in their villages, and who supported us in gaining the confidence of the refugee families during our visits.

\section{Disclosure}

The authors report no conflicts of interest in this work.

\section{References}

1. Moussalli M. Handbook on Procedures and Criteria for Determining Refugee Status under the 1951 Convention and the 1967 Protocol Relating to the Status of Refugees. Geneva: Office of the United Nations High Commissioner for Refugees; 1992.

2. Bean T, Derluyn I, Eurelings-Bontekoe E, Broekaert E, Spinhoven P. Comparing psychological distress, traumatic stress reactions, and experiences of unaccompanied refugee minors with experiences of adolescents accompanied by parents. J Nerv Ment Dis. 2007;195(4): 288-297.

3. Fullilove MT. Psychiatric implications of displacement: contributions from the psychology of place. Am J Psychiatry. 1996;153(12): $1516-1523$.

4. Geltman PL, Augustyn M, Barnett ED, Klass PE, Groves BM. War trauma experience and behavioral screening of Bosnian refugee children resettled in Massachusetts. J Dev Behav Pediatr. 2000;21(4):255-261.

5. Davidson JR, Hughes D, Blazer DG, George LK. Post-traumatic stress disorder in the community: an epidemiological study. Psychol Med. 1991; 21(3):713-721.

6. Eker T. Zorunlu Göç Yaşayan Ailelerin İkinci Kuşak Üyelerinin Să̆lık Durumu. Izmit: Kocaeli Üniversitesi; 2006.

7. Sack WH, Clarke G, Him C, et al. A 6-year follow-up study of Cambodian refugee adolescents traumatized as children. J Am Acad Child Adolesc Psychiatry. 1993;32(2):431-437.

8. Sack WH, Him C, Dickason D. Twelve-year follow-up study of Khmer youths who suffered massive war trauma as children. $J$ Am Acad Child Adolesc Psychiatry. 1999;38(9):1173-1179.

9. Derluyn I, Broekaert E, Schuyten G. Emotional and behavioural problems in migrant adolescents in Belgium. Eur Child Adolesc Psychiatry. 2008;17(1):54-62. 
10. Realmuto GM, Masten A, Carole LF, Hubbard J, Groteluschen A, Chhun B. Adolescent survivors of massive childhood trauma in Cambodia: life events and current symptoms. J Trauma Stress. 1992;5(4):589-599.

11. Allwood MA, Bell-Dolan D, Husain SA. Children's trauma and adjustment reactions to violent and nonviolent war experiences. J Am Acad Child Adolesc Psychiatry. 2002;41(4):450-457.

12. Terr LC. Childhood traumas: an outline and overview. Focus. 2003;1(3): 322-334.

13. Davies M, Webb E. Promoting the psychological well-being of refugee children. Clin Child Psychol Psychiatry. 2000;5(4):541-554.

14. Kizilhan JI. Ethik im yezidentum. In: Yousefi HR, Seubert H, editors. Ethik im Weltkontext. Heidelberg: Springer; 2014:159-166.

15. Chambers WJ, Puig-Antich J, Hirsch M, et al. The assessment of affective disorders in children and adolescents by semistructured interview. Test-retest reliability of the schedule for affective disorders and schizophrenia for school-age children, present episode version. Arch Gen Psychiatry. 1985;42(7):696-702.

16. Gökler B, Ünal F, Pehlivantürk B, Kültür EÇ, Akdemir D, Taner Y. Okul Çaği Çocuklari İçin Duygulanim Bozukluklari ve Şizofreni Görüşme Çizelgesi-Şimdi ve Yaşam Boyu Şekli-Türkçe Uyarlamasinin Geçerlik ve Güvenirliği. TurkJ Child Adolesc Ment Health. 2004;11(3): 109-116. Turkish.

17. Kültür SE, Ünal MF, Özusta PŞ. Alkol bağımlılı̆̆ı olan babaların çocuklarında psikopatoloji. Turk Psikiyatri Derg. 2006;17(1): 3-11. Turkish.

18. Lustig SL, Kia-Keating M, Knight WG, et al. Review of child and adolescent refugee mental health. J Am Acad Child Adolesc Psychiatry. 2004;43(1):24-36.

19. Servan-Schreiber D, Le Lin B, Birmaher B. Prevalence of posttraumatic stress disorder and major depressive disorder in Tibetan refugee children. J Am Acad Child Adolesc Psychiatry. 1998;37(8):874-879.

20. Office for National Statistics. Mental Health of Children and Young People in Great Britain, 2004. Basingstoke, UK: Palgrave Macmillan; 2005.

21. Hodes M, Jagdev D, Chandra N, Cunniff A. Risk and resilience for psychological distress amongst unaccompanied asylum seeking adolescents. J Child Psychol Psychiatry. 2008;49(7):723-732.

22. Liebkind K. Self-reported ethnic identity, depression and anxiety among young Vietnamese refugees and their parents. J Refug Stud. 1993;6(1): 25-39.

23. Reijneveld SA, de Boer JB, Bean T, Korfker DG. Unaccompanied adolescents seeking asylum: poorer mental health under a restrictive reception. J Nerv Ment Dis. 2005;193(11):759-761.
24. Fazel M, Reed RV, Panter-Brick C, Stein A. Mental health of displaced and refugee children resettled in high-income countries: risk and protective factors. Lancet. 2012;379(9812):266-282.

25. Sourander A. Behavior problems and traumatic events of unaccompanied refugee minors. Child Abuse Negl. 1998;22(7):719-727.

26. Fazel M, Stein A. The mental health of refugee children. Arch Dis Child. 2002;87(5):366-370.

27. Kunz EF. The refugee in flight: kinetic models and forms of displacement. Int Migr Rev. 1973;7(2):125-146.

28. Silove D. The psychosocial effects of torture, mass human rights violations, and refugee trauma: toward an integrated conceptual framework. J Nerv Ment Dis. 1999;187(4):200-207.

29. Montgomery E. Long-term effects of organized violence on young Middle Eastern refugees' mental health. Soc Sci Med. 2008;67(10): 1596-1603.

30. Fazel M, Wheeler J, Danesh J. Prevalence of serious mental disorder in 7000 refugees resettled in western countries: a systematic review. Lancet. 2005;365(9467):1309-1314.

31. Lindert J, von Ehrenstein OS, Priebe S, Mielck A, Brähler E. Depression and anxiety in labor migrants and refugees - a systematic review and meta-analysis. Soc Sci Med. 2009;69(2):246-257.

32. Weine SM, Becker DF, McGlashan TH, et al. Psychiatric consequences of "ethnic cleansing": clinical assessments and trauma testimonies of newly resettled Bosnian refugees. Am J Psychiatry. 1995;152(4):536-542.

33. Jakobsen M, Demott MA, Heir T. Prevalence of psychiatric disorders among unaccompanied asylum-seeking adolescents in Norway. Clin Pract Epidemiol Ment Health. 2014;10:53-58.

34. Rousseau C. The mental health of refugee children. Transcult Psychiatry. 1995;32(3):299-331.

35. RutterMJ,BishopD, PineD, etal. Rutter's ChildandAdolescent Psychiatry. 5th ed. Hoboken, NJ: Wiley; 2011.

36. Mghir R, Freed W, Raskin A, Katon W. Depression and posttraumatic stress disorder among a community sample of adolescent and young adult Afghan refugees. J Nerv Ment Dis. 1995;183(1):24-30.

37. Sujoldžić A, Peternel L, Kulenović T, Terzić R. Social determinants of health: a comparative study of Bosnian adolescents in different cultural contexts. Coll Antropol. 2006;30(4):703-711.

38. Şeker BD, Aslan Z. Refugee children in the educational process: an [sic] social psychological assessment. J Theor Educ Sci. 2015;8(1):86-105.
Neuropsychiatric Disease and Treatment

\section{Publish your work in this journal}

Neuropsychiatric Disease and Treatment is an international, peerreviewed journal of clinical therapeutics and pharmacology focusing on concise rapid reporting of clinical or pre-clinical studies on a range of neuropsychiatric and neurological disorders. This journal is indexed on PubMed Central, the 'PsycINFO' database and CAS,

\section{Dovepress}

and is the official journal of The International Neuropsychiatric Association (INA). The manuscript management system is completely online and includes a very quick and fair peer-review system, which is all easy to use. Visit http://www.dovepress.com/testimonials.php to read real quotes from published authors. 